\title{
Casa del Migrante de Saltillo. Salud y solidaridad en el fenómeno de la migración centroamericana en tránsito por México
}

\section{Gabriela de la Peña Astorga}

Facultad de Ciencias de la Comunicación, Universidad Autónoma de Coahuila, México. https://orcid.org/0000-0002-5967-0450

\section{Miguel Sánchez Maldonado}

Facultad de Ciencias de la Comunicación, Universidad Autónoma de Coahuila, México. https://orcid.org/oooo-0002-4886-0881

\section{Sergio de Jesús Colunga Corpus}

Facultad de Ciencias de la Comunicación, Universidad Autónoma de Coahuila, México. https://orcid.org/oooo-0001-5722-5153

Recibido: 2 de julio de 2019. Aceptado: 17 de diciembre de 2019.

\begin{abstract}
Resumen
La investigación parte de la identificación de los puntos geográficos que presentan riesgos a la salud de la población migrante centroamericana en su paso por México hacia los Estados Unidos, dadas las condiciones políticas y de inseguridad que caracterizan actualmente a la zona. También, se identifican las prácticas de resiliencia y autocuidado que promueven los actores vinculados al proceso migratorio (personas migrantes, instituciones, organismos de la sociedad civil) y que llevan a cabo bajo una conceptualización de solidaridad que no es uniforme -o está libre de conflictos. Se analizan los significados y las prácticas solidarias que han desarrollado en torno a la salud y a la enfermedad al mismo tiempo en que este fenómeno ha transformado su experiencia vital. La recolección de datos se realizó del año 2015 al año 2018 en la Casa del Migrante de Saltillo, a través de nueve entrevistas semiestructuradas aplicadas a sus administrativos, 2 grupos de enfoque realizados con su cuerpo de voluntarios, 3 grupos de enfoque llevados a cabo con personas migrantes y un sondeo aplicado a cuarenta y siete migrantes.
\end{abstract}

Palabras Clave: Migración centroamericana. México. Ruta de riesgos. Salud. Solidaridad. 


\title{
Casa del Migrante de Saltillo. Health and solidarity in the phenomenon of Central American migration in transit through Mexico
}

\begin{abstract}
The investigation starts with the identification of the geographical points that present risks to the health of the Central American migrant population in their passage through Mexico to the United States, given the political and insecurity conditions that currently characterize the area. Also, the resilience and self-care practices promoted by the actors linked to the migration process (migrants, institutions, civil society organizations) are identified under a conceptualization of solidarity that is not uniform - or is free from conflicts. The meanings and solidarity practices that they have developed around health and disease are analyzed at the same time that this phenomenon has transformed their life experience. Data collection was carried out from 2015 to 2018 at Casa del Migrante de Saltillo, through nine semi-structured interviews applied to its administrators, 2 focus groups conducted with its volunteers, 3 focus groups carried out with migrants and a survey applied to forty-seven migrants.
\end{abstract}

Keywords: Central American migration. Mexico. Route of risks. Health. Solidarity.

Palavras chave: Migração da América Central. México. Rota dos riscos. Saúde. Solidariedade.

\section{Introducción}

La investigación que aquí se presenta tuvo por objetivo caracterizar los riesgos a la salud de las personas migrantes de origen centroamericano en su tránsito por México hacia los Estados Unidos, identificar las prácticas de autocuidado, resiliencia y solidaridad que estos construyen a partir de su experiencia migratoria, así como definir los significados de salud, enfermedad y solidaridad que sustentan las acciones de cuidado de la salud por parte de los migrantes albergados, los administrativos y voluntarios en la comunidad de la Casa del Migrante de Saltillo.

En este trabajo damos cuenta de cómo se construyen, cuáles son los contenidos, qué experiencias determinan y a qué acciones conducen los significados que a los términos salud, enfermedad y solidaridad dan los diversos actores involucrados en la atención a las personas migrantes centroamericanas en su paso por México, a través del análisis de esta dinámica en la Casa del Migrante de Saltillo.

Desde un enfoque fenomenológico (Schutz, [1932] 1993; Berger y Luckman, [1968], 2003;) y con base en la Teoría fundamentada de Strauss y Corbin ([1967], 1998), se buscó comprender la relación entre significados, estrategias y acciones que permiten solventar el estado de indefensión para el cuidado de la salud en que se encuentran los migrantes centroamericanos a lo largo de su tránsito por México. El contexto de inseguridad permanente en el que se lleva a cabo el proceso migratorio centroamericano en territorio mexicano tiene su origen tanto en la expansión del crimen organizado, que los secuestra y extorsiona, como en las políticas de detención y extradición en que el gobierno mexicano se ha concentrado del año 2015 a mayo de 2019 en materia de inmigración.

Al inicio del trabajo de campo, se observó que los riesgos a la salud de los y las migrantes que se encontraban albergados temporalmente en la Casa del Migrante de Saltillo parecía relacionarse directamente con a) las condiciones estructurales de vulneración de sus derechos humanos desde su lugar de origen y a lo largo de toda la ruta a través 
del corredor migratorio, b) la falta de atención a la problemática por parte de las instancias públicas que no los contemplaban en sus políticas como sujetos de derecho, y c) que bajo este escenario de indefensión de la persona migrante, el personal voluntario y administrativo de este organismo de la sociedad civil realizaba acciones de atención sanitaria emergente y de defensa de su derecho a la salud. Lo anterior dio origen a dos preguntas generales que guiaron la estrategia para la recolección de información y el análisis de los resultados: Ante la exposición de riesgos a la salud a la que se enfrentan los migrantes centroamericanos en México así como ante la falta de una estructura pública de atención para ellos, 1) ¿cómo enfrentaban las y los migrantes los riesgos a su salud?, y 2) si los organismos de la sociedad civil no estaban obligados a atender las necesidades sanitarias de la población migrante, pero eran los principales gestores en esta tarea en México ¿era la solidaridad el eje fundamental de sus acciones?

La operacionalización de estas dos preguntas condujo al establecimiento de los siguientes objetivos específicos:

» Identificar la ruta de tránsito de los migrantes centroamericanos en México así como los riesgos a la salud que se presentan a lo largo de su recorrido, dadas las condiciones de inseguridad pública y de falta de una estructura institucional que atienda sus necesidades sanitarias.

" Identificar los contenidos y el proceso de construcción de los significados de salud, enfermedad y solidaridad tanto de los migrantes centroamericanos albergados en la Casa del Migrante de Saltillo como del cuerpo de líderes, administrativos y voluntarios de este organismo de la sociedad civil.

" Analizar la relación entre estos significados y las estrategias de atención a la salud diseñadas por ellos.

En cuanto a la metodología, el trabajo de campo se realizó in situ en la Casa del Migrante de Saltillo (CDMS) de marzo de 2015 a junio de 2018. Desde una aproximación cualitativa se buscó ir desde la comprensión general del contexto sociopolítico en que se presenta la problemática hasta la concreción pragmática de la experiencia sanitaria de la migración, para lo cual se llevaron a cabo secuencialmente: 9 entrevistas semiestructuradas a líderes y personal administrativo, 2 grupos focales con 6 voluntarios, 3 grupos focales con 10 personas migrantes ( 7 hombres y 3 mujeres) y un sondeo que fue aplicado a 47 migrantes ahí albergados en el mes de julio de 2017 (43 hombres y 4 mujeres; con un promedio de edad de 28 años, donde el valor menor fue de 9 años y el mayor de 63). Por su parte, para la caracterización de la ruta de tránsito de la migración centroamericana en México, se recurrió al contraste de la información obtenida a través de las entrevistas, los grupos focales y el sondeo, con los informes emitidos en los años del 2015 al 2018 por REDODEM y Arquitectos con la gente, A.C.

Para el análisis de los resultados, se retomó la definición de solidaridad normativa de Young (2011) y de solidaridad como justicia social de Brunkhorst (2002, cit. en Arango, 2013), así como las nociones de resiliencia de Tobón Correa (2003) y de autocuidado de la salud de Koselleck (1993). Estos constructos teóricos permitieron comprender las categorías que emergieron de los resultados como respuesta a las preguntas de investigación.

En este trabajo se presenta el contexto sociopolítico del fenómeno de la migración centroamericana en México, la caracterización de riesgos a la salud de los migrantes a lo largo de su ruta por el territorio mexicano, así como los significados de salud, enfermedad y solidaridad que dan como resultado el desarrollo de estrategias de trabajo para la resiliencia, el autocuidado y la defensa del derecho a la salud por parte de migrantes y miembros de los organismos de la sociedad civil. 
En los siguientes apartados se describen cuáles son las rutas por las que viajan las personas migrantes que han llegado hasta la Casa del Migrante de Saltillo, los principales retos y riesgos a la salud a los que se enfrentan en ellas, así como las organizaciones, personas voluntarias e instituciones gubernamentales que les brindan apoyo.

A partir de lo anterior, se desarrolla en este trabajo una caracterización de las estrategias de resiliencia y centradas en el autocuidado de la salud que se asocian a la construcción de una cultura de solidaridad -en algunos casos de origen filosófico y, en otros, como parte de una lucha por consolidarla como principio normativo- en la interacción de las personas involucradas en el tránsito de los migrantes centroamericanos en su paso por México.

\section{Contexto sociopolítico de la migración centroamericana en México}

La falta de una política integral, transversal y transnacional que atienda la crisis humanitaria de la migración en el Continente Americano que tiene en este 2019, junto a Venezuela, su mayor exponente en el flujo de Centroamérica a Norteamérica, coloca a México como país expulsor, de tránsito y receptor. Lo anterior ha desencadenado un nuevo fenómeno de movilización humana en el corredor americano que responde a las nulas condiciones de seguridad y de garantía de los derechos humanos de punta a punta del trayecto para las personas que, ante ningún otro escenario posible de desarrollo en sus lugares de origen, emprenden esta ruta migratoria. Ejemplo de ello es la llamada caravana migrante, término utilizado en la prensa mexicana para referirse al tránsito colectivo de un promedio de 5.000 personas que en los meses de octubre de 2018 a abril de 2019 después de cruzar la frontera sur de México en el estado de Chiapas, recorrieron juntos una distancia de más de 2.000 kilómetros hasta la frontera norte del país, ubicada en los seis estados de la República Mexicana que limitan con los Estados Unidos de América, que son Tamaulipas, Nuevo León, Coahuila, Sonora, Chihuahua y Baja California Norte.

El 1 de julio de 2019, la prensa daba cuenta del despliegue de 15.000 elementos de la Guardia Nacional en la frontera norte de México que habrían de detener el paso de los migrantes centroamericanos hacia los Estados Unidos (AFP, 2019). Al mismo tiempo, 6.500 otros elementos de la misma guardia -compuesta por policías militares, navales y federales- tenían la orden de detener a migrantes indocumentados en la frontera sur y ponerlos a disposición del Instituto Nacional de Migración (Human Rights Watch, 2019).

El recrudecimiento de las órdenes del gobierno federal, del año 2015 a la fecha, de aprehender y deportar a extranjeros indocumentados en territorio mexicano, ha aumentado los riesgos a la salud física y mental de las personas migrantes, que se enfrentan a nuevos peligros ambientales y sociales al transitar por rutas cada vez más hostiles.

Las estaciones migratorias, por su parte, son los centros de detención temporal del gobierno federal en los que se conduce a los migrantes que han sido aprehendidos en México por transitar sin documentos oficiales. Estos se ubican a ambos lados de la frontera México-Estados Unidos de América y en los puntos del territorio nacional que coinciden con las vías férreas. La violación a los derechos humanos de los migrantes tanto en los actos de detención como durante su reclusión en las estaciones migratorias ha desbordado a los albergues de la sociedad civil que, ante la incapacidad del Estado por brindar servicios sanitarios y de seguridad a esta población, han tenido que intensificar sus actividades de atención a esta crisis emergente, así como las de defensa de los derechos humanos. 
En el Informe Mundial 2019 de Human Rights Watch, Kenneth Roth destaca en su análisis de la violación a los derechos humanos en materia de migración que con respecto a la movilidad en el corredor americano durante el año 2018: El presidente Trump utilizó la amenaza percibida de una caravana de solicitantes de asilo que huían de la violencia en Centroamérica para movilizar su base política justo antes de las elecciones al Congreso del país. Fue tan lejos como desplegar 5.000 tropas estadounidenses a lo largo de la frontera con México en una despilfarradora maniobra política. También ordenó la separación de niños inmigrantes de sus padres y restringió ilegalmente el derecho de los solicitantes de asilo a presentar su caso a su llegada a la frontera.

En el mismo sentido, el Observatorio del Colegio de la Frontera Norte (COLEF) en Tijuana, destaca lo siguiente en las reflexiones finales de su análisis "La caravana de migrantes centroamericanos en Tijuana 2018-2019 (Segunda etapa)", en el que aborda el flujo y el impacto social de la llegada de más 6.000 migrantes centroamericanos a la ciudad en noviembre de 2018:

Este escenario [la migración en caravana, como respuesta de las personas migrantes ante las condiciones de inseguridad transnacional] exige al Estado mexicano, en sus tres niveles de gobierno, la elaboración, instrumentación, seguimiento y evaluación de una política migratoria transversal a las instituciones gubernamentales, con perspectiva de derechos humanos y capaz de atender de forma integral las principales necesidades de la población migrante en función de las particularidades de los flujos (COLEF, 2019:9).

Cuestión que, originada en la violación a los derechos humanos, no ha sido resuelta hasta ahora por los gobiernos que componen el corredor migratorio americano; lo que ocasiona, a su vez, situaciones de emergencia y tensión en las relaciones entre instituciones públicas y organismos de la sociedad civil en materia de atención a la salud y de respeto a los derechos humanos de las personas migrantes en México.

\section{Rutas migratorias y riesgos a la salud}

Según la Organización Internacional para las Migraciones (OIM) existen diversos corredores migratorios a lo largo y ancho del planeta. Los corredores son áreas en donde el proceso migratorio es numeroso y constante, generalmente estos van de sur a norte (Latinoamérica-Norteamérica o África-Europa). El corredor más grande, según la OIM (2016), se encuentra en América y comprende las áreas denominadas como Mesoamérica (Centroamérica y México), Norteamérica (Estados Unidos de América y Canadá) y El Caribe. El país destino de este corredor es Estados Unidos de América, mientras que los países de origen se ubican en El Caribe y Centroamérica, además de México; lo que convierte geográficamente a esta última nación en territorio de tránsito y, debido a las políticas migratorias actuales de los EE. UU. y México, en país de retorno y acogida.

En el último reporte del Alto Comisionado de las Naciones Unidas para los Refugiados (ACNUR, 2018) se informa que existen aproximadamente 68,5 millones de personas desplazadas (refugiados) alrededor del mundo, en el mismo sentido la OIM (2015) reporta que cerca de 244 millones de personas han abandonado su lugar de origen en busca de un mejor panorama de vida. En el caso específico de México, el Instituto Nacional de Migración (INM) manifiesta en su reporte cuatrimestral: Estadística reciente de personas presentadas ante la autoridad migratoria, que en los primeros cuatro meses del 2019 se generaron 51 mil 607 reportes de personas migrantes presentadas ante el Instituto, no obstante, esta cifra solo reporta los casos formales (INM, 2019). 
Aunque de acuerdo con las opiniones de los miembros de la Casa del Migrante se estima que las cifras de personas migrantes que cruzan la frontera de manera informal, es mucho mayor.

En México existen ocho cruces fronterizos formales en las que las autoridades nacionales controlan el flujo humano y mercantil que ingresa al país; por otro lado, la Secretaría de Relaciones Exteriores (SRE), a través de la Comisión Internacional de Límites y Aguas México-Guatemala (CILA), ha detectado 56 entradas informales entre Guatemala y México, en donde no existe control de ingreso-egreso (ver Figura 1). Los datos reales de las personas migrantes que transitan por el país son difíciles de precisar debido al claro movimiento informal entre ambas regiones.

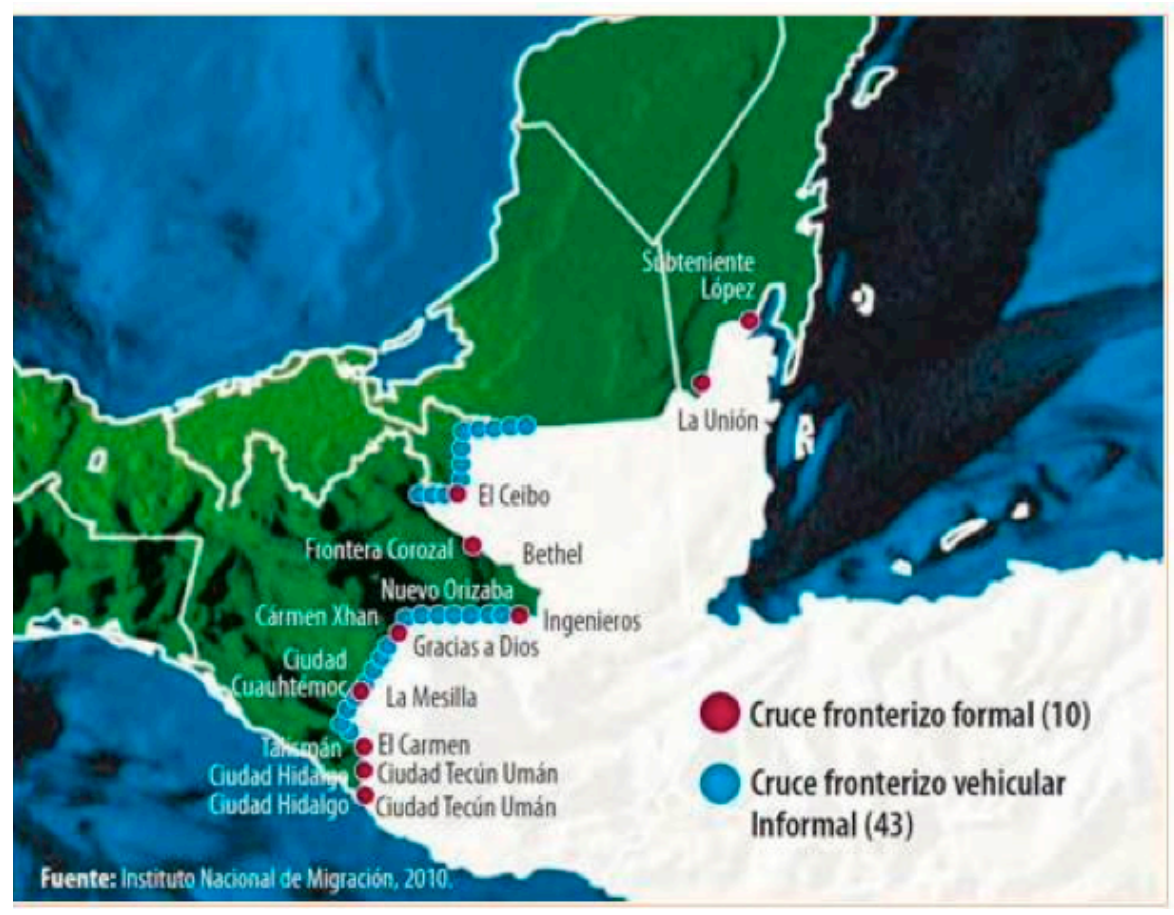

Figura 1. Puntos de cruce en la frontera sur de México. Fuente: INM (2010), publicado en Zamudio (2015).

En el mismo sentido, el rastreo de las rutas migratorias se dificulta. Las asociaciones civiles encargadas de brindar apoyo a las personas migrantes, realizan esfuerzos para elaborar un mapa en el que se muestren las vías más concurridas por la población migrante a partir de las entrevistas que les son realizadas; sin embargo, el desconocimiento de la geografía mexicana por parte de los centroamericanos y caribeños, el cambio en los movimientos de los grupos del crimen organizado en territorio mexicano y las modificaciones de una política migratoria cada vez más persecutoria, complican el proceso de recolección y actualización de datos (Canales Cerón y Rojas Wiesner, 2018; OIM, 2018).

Existen reportes como el de la Red de Documentación de las Organizaciones Defensoras de Migrantes (REDODEM), en los cuales se detallan los datos estadísticos más relevantes referentes a la migración sur-norte del corredor americano. Cuando los migrantes ingresan a alguna asociación miembro de la Red, se realiza una entrevista de entrada, en la cual se registran datos sociodemográficos, sus condiciones de salud y los casos de violaciones de derechos humanos, entre otros temas. De esta manera, los albergues realizan un informe a través del cual es posible conocer, de 
manera general, estadísticas sobre las personas migrantes. La información que se presenta a continuación está basada en el informe anual de la REDODEM en su edición del 2017.

El número de personas migrantes que se albergan en las organizaciones que pertenecen a la REDODEM (2018), varía cada año. La cifra oscila entre las 28 mil y 30 mil personas. Sin embargo, los datos que permanecen constantes, sin importar el número de personas, son: el género, la edad, las razones de salida y la ocupación. Respecto al país de origen, según el informe, se recibe principalmente a personas provenientes de Honduras, en segundo lugar de El Salvador, mientras que en los últimos puestos se encuentran los originarios de Guatemala y Nicaragua; pertenecientes a lo que los organismos de la sociedad civil denominan "Triángulo Norte de Centroamérica” (Suárez et al., 2017). De acuerdo con el género, el porcentaje de hombres que fueron registrados formalmente como migrantes en 2018 (REDODEM, 2018) es de 93,11\%, 6,82\% de mujeres y, el $1 \%$ restante comprende a las personas transgénero y transexuales. En cuanto a porcentajes por edad, los jóvenes y jóvenes adultos son quienes más cruzan $(56,94 \%)$, posteriormente se encuentran los adultos (22,99\%), seguidos por los adultos mayores $(11,29 \%)$, y niños y adolescentes $(8,12 \%)$.

Durante los años 2016 y 2017, aumentó el porcentaje de migrantes de origen africano, haitiano y cubano; y durante el año 2018, REDOMEM reportó el aumento en el porcentaje de personas migrantes de 0 a 11 años de edad, así como en el de las mujeres.

Según el mismo informe, entre los factores por los que las personas migrantes centroamericanas en México deciden o se ven forzados a salir de su país de origen, están: 1) los económicos; falta de oportunidades de un empleo digno, la búsqueda de una mejor calidad de vida, empleo mal remunerado y deudas, 2) el contexto generalizado de violencia; persecución por el crimen organizado, violencia doméstica, persecución política y discriminación por orientación y/o identidad sexual y 3) razones familiares; reunificación familiar y/o búsqueda de un familiar. Así mismo, de forma mayoritaria, el nivel de estudios de los entrevistados no supera la educación básica o no cuentan con ningún estudio $(87,78 \%)$. En contraste, las personas con una educación media o media superior solo representan el 12,22\%. En relación con lo anterior, los informantes declaran participar más en actividades económicas primarias y secundarias, como la agricultura, la ganadería, la pesca, la minería y manufactura. De modo que el perfil predominante de los migrantes centroamericanos en México es el siguiente: Hombres hondureños de 18 a 30 años, dedicados a las labores del primer sector en recolección agrícola y con escolaridad básica, trunca o sin estudios; siendo los factores económicos la razón principal por la cual emigran (REDODEM, 2018).

En el mismo sentido, otra iniciativa civil cuyo fin es la investigación en temas de migración, es "Arquitectos con la gente", que retrata el camino de las ciudades mexicanas por las que cruzan las personas migrantes con base en las rutas ferroviarias del país. Según la iniciativa, son 27 las ciudades mexicanas donde las personas migrantes hacen escala (Ver Figura 2). 
DIAGRAMA DE RUTAS MIGRANTES

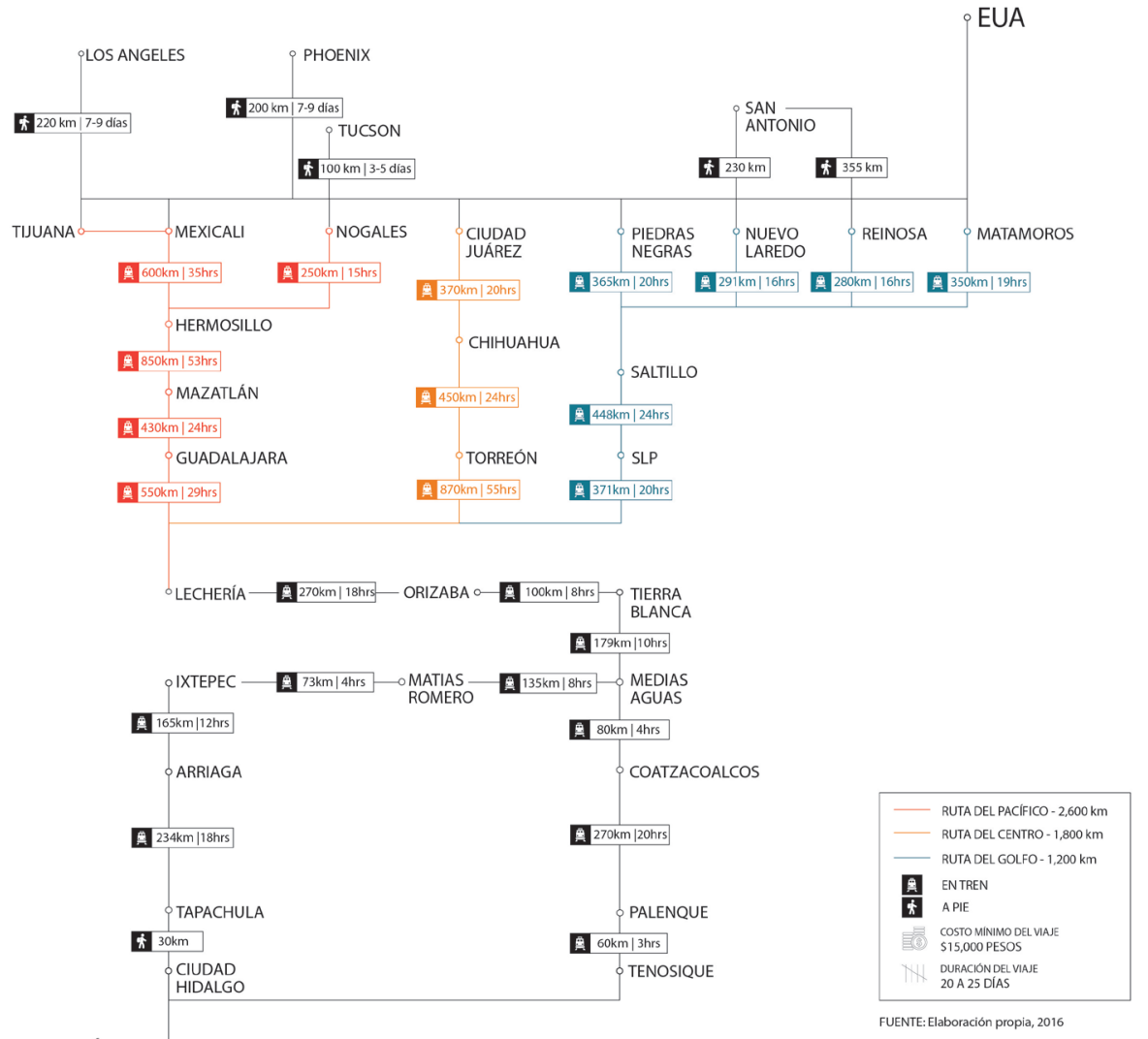

MÉXICO

Figura 2. Mapeo Ruta Migrante. Fuente: Arquitectos con la gente (2016).

Esta información, en conjunto con los datos ofrecidos en el informe de la REDODEM (2017), permiten realizar un reconocimiento de los riesgos que las personas migrantes enfrentan en su seguridad y la salud a partir de las condiciones geográficas, climáticas y sociales de los lugares por los que transitan, que más adelante serán contrastados con la información del trabajo de campo realizado en esta investigación.

Por ser el tren de carga el medio de transporte más utilizado por las personas migrantes en su camino hacia Estados Unidos a lo largo del territorio mexicano, en este apartado se presenta una descripción de su utilización relacionada con este fenómeno. Las rutas ferroviarias están divididas en ocho, algunas se encuentran situadas en el sur, otras en el norte y otras van de sur a norte. Sin embargo, para los migrantes centroamericanos, las ocho rutas se convierten en una sola con diferentes entradas y salidas. El tren de carga es utilizado como transporte debido a que es el medio más rápido para cruzar el país, y permite ocultarse de las autoridades migratorias.

Para obtener un panorama más claro de la ruta migratoria, ésta puede ser dividida en tres. Primero, el ingreso, que comprende la zona sur del país: Chiapas, Tabasco, Veracruz, Estado de México. Estos tienen características geográficas de selva a bosque tropical con clima cálido húmedo y subhúmedo, además de tener los más altos índices de marginación social en el país. Segundo, el centro de la ruta en los estados de Guanajuato, Jalisco y San Luis Potosí, con características geográficas de mesetas y montaña de clima templado y seco, con zonas urbanas desarrolladas y un nivel de marginación social inferior a la media nacional. Finalmente, la frontera que comprende los estados 
de la franja norte del país: Tamaulipas, Nuevo León, Coahuila, Chihuahua, Sonora y Baja California Norte, el territorio de estos estados es desértico con clima seco y árido, estos estados son los más afectados por la inseguridad y violencia desde 2009 (CONAPO, 2016; INEGI, 2019; IEP, 2019).

Las rutas del sistema ferroviario son el medio de transporte mayormente utilizado por las personas migrantes en México para realizar el trayecto a lo largo del país; éste recorre 19 de las 32 entidades federativas del país. Según los informes de la REDODEM, desde el año 2016, Chiapas y Tabasco han sido los estados con mayor índice de inseguridad para las personas migrantes, seguido por Ciudad de México, Jalisco y Guanajuato, y al final de la lista, se coloca a Chihuahua, Tamaulipas y Coahuila; orden que la misma organización reportó haberse modificado durante el año 2018 debido al control que los grupos del crimen organizado han establecido en la ruta del Golfo y del Centro, así como por las condiciones de violencia e inseguridad en la frontera noreste del país. Así, para el último año, la REDODEM reporta que es la ruta de Occidente -comprendida por los estados de Nayarit, Jalisco, Colima y Michoacán- la que mayor densidad de tránsito presenta en nuestro país. En su informe 2018, titulado El Estado indolente: recuento de las violencias en las rutas migratorias y perfiles de movilidad en México, REDODEM da cuenta de las consecuencias que tuvo la política pública de migración en México como violencia institucional ejercida por autoridades federales, estatales y municipales hacia las personas migrantes a través de acciones de aprehensión, encarcelamiento y deportación sin respeto a sus derechos humanos.

Esto ha ocasionado que, desde el año 2015, las personas migrantes tomen medios de traslado alternativos al tren durante su ruta -tales como la caminata en grupo y contratación de recorrido en camiones de carga de forma clandestina- que presentan riesgos aún mayores para su salud e integridad física (REDODEM, 2015). Según el informe, los riesgos más comunes, referentes a seguridad y violencia, son: abusos sexuales, trabajos forzados, secuestro, extorsión y robo a mano armada; y en temas de salud, desde picaduras o ataques de animales salvajes, hasta la deshidratación y/o desnutrición.

Las personas migrantes han optado por recorrer su camino sin la ayuda de vehículos motorizados, recorriendo a pie poblados cercanos a las rutas férreas e incluso atravesando zonas inhóspitas, exponiéndose a picaduras o ataques de animales, extravío, deshidratación o desnutrición según indica el reporte anual de REDODEM 2016. Además, se enfrentan a riesgos y peligros psicosociales en las diferentes etapas de su trayecto: el trauma del momento de salida, tránsito, cruces de fronteras y llegada al país de destino. Los impactos acumulados sobre sus cuerpos se ven reflejados en los estados de salud recogidos en la base de datos de esta institución: cansancio, gripe, lesiones en los pies, golpes, dolor de cabeza, deshidratación (REDODEM, 2017).

Por lo anterior, la OIM (2018) considera que la migración debe ser catalogada como un factor social determinante para la salud en todos los sentidos. El conjunto de estos factores retrasa el cumplimiento de los objetivos nacionales e internacionales de salud, como son la prevención del VIH, la contención de la tuberculosis, el paludismo y la gripe aviar humana.

Las personas migrantes que cruzan el territorio mexicano para llegar a Estados Unidos sin documentación o registro ante las autoridades mexicanas, suelen padecer aún más que los que sí cuentan con ella. La situación de estancia irregular en México obliga a las personas migrantes a prescindir de derechos básicos como la salud, la educación, el trabajo o el transporte (Canales Cerón y Rojas Wiesner, 2018).

La Organización Mundial de la Salud (OMS) señala que los problemas de salud más frecuentes entre los refugiados y migrantes son las lesiones accidentales, la 
hipotermia, las quemaduras, los accidentes cardiovasculares, las complicaciones del embarazo y el parto, la diabetes y la hipertensión. Las mujeres migrantes se enfrentan a dificultades específicas en el ámbito de la salud materna, del recién nacido y el niño, de la salud sexual y reproductiva, y de violencia (Organización Mundial de la Salud, 2016).

En cuanto a las estaciones migratorias mexicanas -centros públicos de detenciónBotero y Gordon hacen referencia en su estudio a las condiciones precarias, y en algunos casos insalubres, en las que se encuentran las instalaciones, la alimentación y el acceso a los servicios de la salud básica física y psicológica de los migrantes detenidos, así como a la falta de comunicación que deben tener con sus familiares y de acceso a la asistencia legal. Los autores destacan que "en términos generales, las instalaciones y el trato a los internos en las estaciones migratorias no se corresponden con la naturaleza administrativa de la detención de migrantes" (Botero y Gordon, 2013: 44).

En otro reporte conducido por Barja Coria sobre las condiciones de los centros de detención para migrantes en diferentes estados de la república mexicana, se encontró que, en relación con la salubridad, las instituciones cuentan con espacios reducidos sin las adaptaciones necesarias para que la gente se establezca ahí, que no se hace limpieza en las habitaciones, que los artículos de higiene que reciben son limitados y que la comida que se les brinda no está en buen estado. Respecto a la atención médica, solo se les proporciona si la piden y, en algunos casos, se demora por falta de personal. Por ejemplo, en el caso de la estación de Saltillo, Coahuila se menciona que "a pesar de contar con espacio suficiente, las instalaciones necesitan mantenimiento, no se hace limpieza de las habitaciones, a quienes usan la ropa de cama les produce picazón y en temporada invernal no se cuenta con lo necesario para pasar el frío" (Barja Coria, 2015: 112).

En el aspecto de la salud mental es casi nula la ayuda que llegan a recibir las personas migrantes. En casos de crisis se les brinda atención psicológica a través de los Centros de Salud Mental (CESAME), pero en cuanto la persona se encuentra bajo control, ésta vuelve a ser recluida en el centro de detención (Barja, 2105: 113).

Aunada a las deficiencias estructurales de las estaciones migratorias y centros de detención de los migrantes, existen otros factores de riesgo culturales que atentan contra la salud de las personas en tránsito, sobre todo en el mantenimiento del autoconcepto, autoestima y resiliencia. López (2013) comenta que la vulnerabilidad de los migrantes centroamericanos en la Región Lagunera (Zona Metropolitana de Torreón, Coahuila y Gómez Palacio, Durango) tiene facetas marcadas por el racismo construido en el imaginario de algunos mexicanos que los ven como delincuentes, portadores de enfermedades contagiosas y extranjeros no sujetos de derechos o de acciones solidarias. En palabras del autor:

El desconocimiento de la sociedad, la insensibilidad, hace recrudecer el apoyo que otros actores puedan otorgar a este fenómeno, pues la intolerancia, la discriminación y la xenofobia son elementos que están presentes, por lo cual la ayuda humanitaria no es suficiente para auxiliar a los hombres, mujeres y niños que buscan tan sólo apoyo humanitario (López, 2013: 29).

Leyva et al (2015) exponen, a través de una investigación realizada en ocho casas y albergues de migrantes localizados en diferentes puntos de México, la noción errónea que existe entre la población mexicana respecto a la persona migrante como portadora de enfermedades, pues son las condiciones del trayecto en el territorio nacional, y no las del país de origen, lo que genera el deterioro de la salud de los migrantes. 


\section{Instituciones y organismos solidarios con la salud de migrantes centroamericanos en México}

La solidaridad en sociedades democráticas debe ser entendida como justicia social (Brunkhorst, 2002; cit. en Arango, 2013) o bien, como obligación restitutiva de un daño de origen estructural cometido contra determinados grupos que impide contar -nacional e internacionalmente- con unos "deberes recíprocos universables", de acuerdo con Brunkhorst (2002; cit. en Arango, 2013), y con un estado en que sean posibles las "recíprocas exigencias que nos hacemos", en términos de Young (2011). Para Young, la solidaridad es una responsabilidad social ante la injusticia estructural, y no un mero valor individual o solo un sentimiento que motiva la acción civil colectiva. Como tal, propone que ésta sea un principio normativo a nivel jurídico y político, basado en las fácticas relaciones de interdependencia y necesaria "interconexión" en un mundo globalizado, que bien podría retomar la definición de "solidaridad orgánica" de Durkheim (1928), en tanto el apoyo a las causas de otros no se basa en relaciones sociales afectivas o morales; sino en relaciones imprescindibles para la supervivencia humana.

Hablamos de la solidaridad como mutuo auxilio y colaboración que, de ser integrado positivamente al Derecho, anticipa mejores relaciones y da cabida a la libertad y a la igualdad universales (Brunkhorst, 2002, cit. en Arango, 2013), al reconocer el perjuicio colectivo de origen estructural realizado en el pasado y/o el presente por otro común normativo. Los derechos humanos, en los que se incluye el derecho a la salud, operan de este modo bajo el principio legislativo de solidaridad.

En México existen diversas redes de asociaciones, organizaciones civiles y particulares dedicadas a salvaguardar y defender la integridad de las personas migrantes y sus derechos humanos. A lo largo de la República Mexicana se encuentran aproximadamente 75 albergues, contando solamente a los de origen católico, en los cuales se brinda atención biopsicoeducativa y jurídica a la población migrante que transita por México, según reporta la Conferencia del Episcopado Mexicano a través de su Observatorio Nacional (2017); apoyados, en mayor o menor medida en cada una de las entidades federativas, por organismos internacionales como la Comisión Interamericana de Derechos Humanos (CIDH), Amnistía Internacional, la oficina del Alto Comisionado de Naciones Unidas para los Refugiados (ACNUR) y Brigadas de Paz Internacionales (PBI); ésta última, incluso, se ocupa de la protección de los defensores de derechos humanos en territorio mexicano. Hasta ahora, dependiendo del papel que a este flujo migratorio le otorgan los gobiernos estatales y municipales en México, también participan en la atención a la salud de las personas migrantes, instituciones públicas y/o autónomas como las comisiones de Derechos Humanos o las secretarías de Salud pública y Relaciones exteriores.

Mientras la política federal para la atención a la migración centroamericana en México continúa definiéndose al momento de escribir este trabajo -debido a los nuevos acuerdos internacionales entre los países involucrados en el flujo del corredor americano-, son iniciativas civiles como las mencionadas anteriormente (Arquitectos con la gente, REDODEM y los albergues pertenecientes al Episcopado Mexicano) las que a lo largo de los últimos 20 años han desarrollado mecanismos de protección a las personas migrantes que incluyen, además de actividades de hospedaje, alimentación y atención psicomédica, asesoría legal, activismo e incidencia política así como investigación y documentación sobre el fenómeno migratorio. Su tendencia ha sido avanzar en la creación de un marco legal basado en la solidaridad normativa mientras realizan acciones urgentes en contraposición, sobre todo del año 2015 a la fecha, a las estrategias gubernamentales de detención y deportación (Cabrera, González y Paz, 2017) así como al secuestro, asesinato y extorsión de que son presas los migrantes centroamericanos por parte de grupos delictivos en las tres regiones de la ruta migratoria en México. 


\section{La Casa del Migrante de Saltillo}

El complejo panorama del fenómeno migratorio centroamericano en México descrito en páginas anteriores representa las condiciones bajo las que opera la Casa del Migrante de Saltillo (CDMS), organismo de la sociedad civil que fue seleccionado como escenario de estudio de esta investigación. Fundada en el año 2002 como albergue de origen católico y sede de la asociación civil "Frontera con justicia", la CDMS es en México y en América Latina un referente como modelo de organización de atención a la población migrante ${ }^{1}$. En el Informe del Plan de Acción Brasil (2014-2017) Grupo Articulador México, del cual forma parte, se define a la Casa del Migrante de Saltillo - Frontera con Justicia, A.C. como "organización de la sociedad civil sin fines de lucro ni filiación partidista que se dedica a la promoción y defensa de los derechos humanos de personas migrantes y solicitantes de la condición de refugiado en Coahuila".

Perteneciente a la Diócesis de Saltillo, la CDMS ha establecido una estructura organizacional que atiende diariamente a un promedio de 100 personas entre migrantes, voluntarios, consejo administrativo y equipo de trabajo, que intervienen en los dos principales problemas que los migrantes en México, de mayoría centroamericana, enfrentan en su ruta migratoria: salud y atención jurídica. Los migrantes que han llegado hasta sus puertas, generalmente, lo hacen al bajar de los vagones del tren cuya ruta de paso se ubica a 50 metros del albergue y como parada previa (última o penúltima) a su cruce por la frontera México-Estados Unidos.

Lo que hace particular en temas de salud y de solidaridad a este albergue, son las condiciones de salud mental y física en que las personas migrantes se acogen a su hospedaje y asesoría después de haber cruzado el territorio mexicano a lo largo de 2000 kilómetros y de 10 estados de la República Mexicana, en promedio; en un trayecto que es impredecible en su duración y en los riesgos a su integridad física; razón que explica, como se verá en los resultados de esta investigación, que el perfil mayoritario de los integrantes del colectivo en la ruta migratoria sean hombres en edades de 20 a 30 años.

\section{Atención a la salud en la CDMS y construcción de conceptos: salud, enfermedad, resiliencia, autocuidado y solidaridad}

A continuación se definen la organización y las acciones realizadas en la Casa del Migrante de Saltillo en atención a la salud de las personas migrantes, a partir de las cuales se advierte que el eje que dinamiza esta atención por parte de los involucrados (migrantes, instituciones, voluntarios y administradores) es un concepto de solidaridad que, no obstante ser reconocido por todos, es conceptualizado de forma diversa, desde su experiencia, por parte de cada uno de los grupos involucrados. Lo mismo sucede con respecto a los significados de salud y enfermedad, de autocuidado y resiliencia.

\section{Atención médica y jurídica: estrategia ante la falta de estructura pública en el respeto a los derechos humanos de las personas migrantes}

Los resultados de la investigación arrojan que la percepción que tienen los actores involucrados en la salud de la población migrante en la CDMS sobre el desempeño de las instituciones públicas en México, es que éstas no se preocupan por la atención a la salud de los y las migrantes, al verse rebasadas por la demanda que existe de este

1 La labor de la Casa del Migrante de Saltillo puede ser revisada en la siguiente nota del diario La Jornada, en ocasión del Premio Internacional de Derechos Humanos Letelier-Moffitt que le fue otorgado en el año 2011: http://www. proceso.com.mx/283840/premian-a-casa-del-migrante-de-saltillo 
servicio por parte de nacionales. Los migrantes opinan que, no han tenido contacto con el personal de salud pública, o la experiencia de servicio es deficiente e "informal". Los voluntarios y personal administrativo de la CDMS expresan, por su parte, que no se respetan los derechos a la salud de los migrantes; que el personal de las instituciones de salud pública no conoce la legislación al respecto y que no han implantado protocolos de atención a esta problemática. La enfermedad, opinan, es entendida en las instituciones públicas solo como atención a enfermedades contagiosas o accidentes. También opinan que la defensa de los derechos humanos incluye el derecho a la salud, y que la solidaridad de las instituciones públicas en este aspecto, no debería ser voluntaria; si no normativa y garantizada por el Estado.

Los protocolos que siguen las organizaciones civiles cuando una persona ingresa sus albergues y presenta alguna sintomatología, se dividen en tres: Atención Básica, Atención Especializada y Atención Urgente. La clasificación de la enfermedad varía dependiendo de la gravedad de las manifestaciones corporales que presente la persona migrante. En Atención Básica se atienden las enfermedades que pueden ser tratadas con los medicamentos que están disponibles en el albergue: resfriados, dolor de garganta, heridas menores, dolor de cabeza, dolores musculares, entre otras. Para tratar los dolores musculares o resfriados, las personas son atendidas, complementariamente, con medicina alternativa. El tratamiento recibido incluye masajes corporales o tratamientos herbolarios que comúnmente son realizados por personas que pertenecen a la comunidad.

Por otro lado, la Atención Especializada se brinda a las personas que muestran síntomas más complejos o que requieren de medicamentos controlados, en estos casos las personas son canalizadas con los médicos voluntarios. Los médicos asisten una o dos veces por semana y pertenecen a la red de voluntarios gestionados por la organización. Generalmente, son estudiantes de últimos semestres de las carreras de Medicina y Enfermería de las escuelas públicas o privadas de la región. En la CDMS, se cuenta con la participación de una médica general, un cardiólogo, un ginecólogo y una enfermera.

Por último, la Atención Urgente se brinda a personas que presentan una enfermedad que sobrepasa la capacidad de la organización; enfermedades crónicas como cáncer, diabetes, hipertensión o lesiones graves ocurridas en el transcurso de su viaje. El personal administrativo se reúne y evalúa las posibles líneas de actuación, a partir de lo cual, las personas son dirigidas a instituciones gubernamentales o bien, a las autoridades migratorias, dependiendo del grado de avance de su enfermedad.

Alberto Xicoténcatl, director de la CDMS, menciona que las personas migrantes en el Estado de Coahuila tienen derecho al Seguro Popular ${ }^{2}$ por un periodo de tres meses, por lo que, si están diagnosticadas con cáncer, no tendrían oportunidad de seguir con el tratamiento una vez terminado el tiempo límite. En caso de ser así, se le explica a la persona migrante sus opciones y se le acompaña en los trámites que necesite realizar. Los agentes de migración tienen la responsabilidad de regresar a los migrantes sanos a su país de origen, esta información es explicada al enfermo para que pueda tomar una decisión. Por otro lado, si la enfermedad es tratable en el periodo de tres meses, la participación de los voluntarios y personal administrativo, e incluso de otros migrantes del albergue, se hace presente de forma más notoria, ya que algunos pacientes tienen la necesidad de estar acompañados durante su estancia en el hospital o en la CDMS.

2 Establecido en México durante el periodo presidencial de 2001-2006, el Seguro Popular es el programa federal de prestación de servicios médicos dirigido a las familias no derechohabientes de seguridad social, al que pueden incorporarse grupos organizados de la sociedad. El costo es cubierto mediante un subsidio federal proveniente de recursos fiscales del Presupuesto de Egresos de la Federación y de las aportaciones familiares de los asegurados. El monto de la aportación familiar es determinado según el nivel de ingreso de cada familia. 
Además, la organización cuenta con convenios establecidos con diversas asociaciones e instituciones, los más relevantes son con la Secretaría de Salud, el Instituto Nacional de Salud, Cruz Roja Internacional, Médicos sin Fronteras, Organización Internacional de las Migraciones, y con las Facultades de Trabajo Social, Psicología y Medicina de la Universidad Autónoma de Coahuila. La Facultad de Medicina se encarga de realizar pruebas VIH y campañas de vacunación, mientras que la Secretaría de Salud del estado de Coahuila, imparte talleres a las personas migrantes sobre la desnormalización de la violencia y el machismo, y capacita al personal administrativo de la CDMS para que sean sus mismos miembros quienes lo impartan. La Facultad de Trabajo Social ofrece talleres sobre sexualidad, higiene personal y métodos anticonceptivos para las mujeres migrantes.

Las complicaciones más comunes de las personas que ingresan al albergue son aquellas relacionados con el sistema respiratorio y de tipo dermatológico, debido a que se enfrentan a ambientes hostiles, naturales y artificiales, sin protección. Pueden pasar un día entero caminando bajo el sol y por la noche exponerse al frío de las carreteras, sostenerse durante horas con poca oxigenación o sobre el metal a altas temperaturas de los medios de transporte en que recorren parte de su ruta. Además, debido a las grandes caminatas que realizan, sus pies se hinchan o lastiman; es común observar a personas migrantes con llagas en las plantas de los pies y, a raíz de la transpiración, con hongos. Lesiones de tobillo y brazo, contracturas musculares, golpes, deshidratación e insolación también se presentan con frecuencia al ingresar al albergue. Por otro lado, algunas personas experimentan fuertes dolores de cabeza asociados al estrés crónico, a la depresión y al alcoholismo. En ocasiones suelen tener pesadillas o presentar ansiedad. Los problemas de salud bucal también son frecuentes en el albergue. En el caso de las mujeres, particularmente, se agregan las lesiones por agresión sexual y violación; y en el de los hombres, mutilaciones.

El personal voluntario de la CDMS atiende estos problemas al ingreso de las personas migrantes al albergue, con analgésicos comunes en el caso de dolores internos, y realizan curaciones en las heridas externas. A pesar de no ser habitual recibir a personas migrantes con enfermedades contagiosas, la CDMS cuenta con algunas reglas de higiene para dichos casos: apartar utensilios de cocina específicos para la persona contagiada y solicitarle que use cubrebocas y cobijas personales durante su estancia en el albergue.

Además de los conflictos a los que se enfrentarán durante su trayecto, Fernández et al (2014) mencionan que los riesgos a la salud de las personas migrantes deben observarse desde sus comunidades de origen, la forma en la que se desarrollan sus usos y costumbres en relación con la salud y las enfermedades en un entorno de pobreza generalizada; que suelen ser de origen infeccioso y ligados a los trastornos anímicos.

La CDMS cuenta con dos áreas de atención a la salud, que coordinan el primer acercamiento que los estudiantes voluntarios tienen con las personas migrantes, los servicios que los médicos prestan por iniciativa propia y la intervención de las instituciones públicas que cuentan con programas de apoyo. Estas áreas son denominadas Atención humanitaria y Atención psicoeducativa, y se encargan, sobre todo, de diseñar y ejecutar programas de tratamiento emergente a la salud mental. Integradas por psicólogos, trabajadores sociales y líderes de la CDMS con formación de atención espiritual y medicina alternativa, estas áreas intervienen en lo que consideran un problema crónico de depresión, de origen estructural, relacionado con las condiciones de pobreza e inseguridad en que han vivido las personas migrantes en sus lugares de origen, que se ve agravado por el estrés acumulado en su tránsito por el corredor americano, y que puede aumentar a partir de su situación migratoria. El acceso al servicio de salud en los países de tránsito y destino es complicado para esta 
población y en ocasiones suele negárseles; por lo que estas dos áreas son apoyadas por la de Atención jurídica en los casos en que hay que defender su derecho a la salud o interponer alguna denuncia.

La dinámica anterior puede ser entendida a partir tanto de los significados de salud, enfermedad y solidaridad que tienen los actores directamente involucrados, como de las estrategias que estos diseñan y ejecutan en atención al cuidado de la salud.

\section{Significados de salud, enfermedad y solidaridad}

La construcción de estos tres conceptos a partir de la experiencia de los actores participantes (personas migrantes, voluntarios y personal de la CDMS, organismos públicos y privados), da lugar a estrategias de atención y de construcción de un marco cultural que pueda solventar la emergencia del fenómeno y orientarse hacia la consolidación de una estructura integral para la solución del problema de vulneración a la salud y a los derechos del colectivo migrante centroamericano en México.

El siguiente cuadro resume los contenidos del significado que le otorgan las personas migrantes, el personal administrativo de la CDMS así como su cuerpo de voluntarios a los términos de salud, enfermedad y solidaridad en atención a la salud (ver Cuadro 1).

Cuadro 1. Significados de salud, enfermedad y solidaridad en la CDMS. Elaboración propia. (2019)

\begin{tabular}{|c|c|c|c|}
\hline Actor & Significado de salud & $\begin{array}{l}\text { Significado de } \\
\text { enfermedad }\end{array}$ & $\begin{array}{l}\text { Significado de } \\
\text { solidaridad en atención } \\
\text { a la salud }\end{array}$ \\
\hline $\begin{array}{l}\text { Hombres } \\
\text { migrantes }\end{array}$ & $\begin{array}{l}\text { Lo definen como “estar } \\
\text { bien”. Para ellos, es } \\
\text { una actitud más allá } \\
\text { de la enfermedad } \\
\text { física. Consideran que } \\
\text { cualquier enfermedad } \\
\text { se supera, mayormente, } \\
\text { si se tiene una actitud } \\
\text { positiva y una voluntad } \\
\text { férrea por lograr los } \\
\text { objetivos. }\end{array}$ & $\begin{array}{l}\text { Cualquier limitación } \\
\text { física que les impida } \\
\text { lograr sus objetivos } \\
\text { a corto, mediano y } \\
\text { largo plazo. Asociado } \\
\text { a la salud física y a la } \\
\text { concepción del cuerpo } \\
\text { como herramienta de } \\
\text { traslado y trabajo. }\end{array}$ & $\begin{array}{l}\text { Consideran que a lo } \\
\text { largo del trayecto, } \\
\text { desarrollan un sentido } \\
\text { de solidaridad con los } \\
\text { integrantes del colectivo } \\
\text { migrante, sobre todo } \\
\text { hacia los niños, las } \\
\text { mujeres y los hombres } \\
\text { que estén enfermos } \\
\text { y, particularmente, en } \\
\text { situaciones de riesgo a la } \\
\text { integridad física. }\end{array}$ \\
\hline $\begin{array}{l}\text { Migrantes } \\
\text { mujeres }\end{array}$ & $\begin{array}{l}\text { Concebido como un } \\
\text { estado de armonía entre } \\
\text { cuerpo y mente. }\end{array}$ & $\begin{array}{l}\text { Lo definen como } \\
\text { decaimiento en la salud } \\
\text { física, pero, sobre todo, } \\
\text { mental. }\end{array}$ & $\begin{array}{l}\text { Solidaridad en salud es } \\
\text { buscar acompañamiento } \\
\text { emocional y físico de } \\
\text { personas a quienes } \\
\text { consideran honorables. }\end{array}$ \\
\hline Voluntarios & $\begin{array}{l}\text { Conciben a la salud } \\
\text { como un derecho } \\
\text { universal. }\end{array}$ & $\begin{array}{l}\text { Consideran que } \\
\text { la enfermedad es } \\
\text { consecuencia de que no } \\
\text { se respetan los derechos } \\
\text { humanos. }\end{array}$ & $\begin{array}{l}\text { Comprendida en dos } \\
\text { vías: acompañamiento } \\
\text { a las personas } \\
\text { migrantes en su } \\
\text { estado de enfermedad } \\
\text { y procuración de su } \\
\text { salud integral; y, por } \\
\text { otro, de lucha por el } \\
\text { reconocimiento del } \\
\text { derecho universal a la } \\
\text { salud, entre otros, como } \\
\text { derecho humano. }\end{array}$ \\
\hline
\end{tabular}




\begin{tabular}{|c|c|c|c|}
\hline $\begin{array}{l}\text { Personal de } \\
\text { la CDMS en } \\
\text { Atención } \\
\text { Psicopedagógica } \\
\text { y Humanitaria }\end{array}$ & $\begin{array}{l}\text { Se revela una visión bio } \\
\text { psico social de la salud } \\
\text { que integra políticas } \\
\text { públicas, participación } \\
\text { de organismos } \\
\text { gubernamentales y no } \\
\text { gubernamentales. }\end{array}$ & $\begin{array}{l}\text { Las personas migrantes } \\
\text { son personas } \\
\text { dinamitadas en su salud } \\
\text { emocional; pero no se } \\
\text { dan cuenta de ello hasta } \\
\text { que salen de su lugar de } \\
\text { origen. A lo anterior, hay } \\
\text { que sumar el estrés del } \\
\text { trayecto. }\end{array}$ & $\begin{array}{l}\text { El cuidado de la } \\
\text { salud mental es } \\
\text { imprescindible para } \\
\text { mejorar las condiciones } \\
\text { de vida de las personas } \\
\text { migrantes. Por ello, se } \\
\text { trabaja integralmente } \\
\text { buscando el apoyo de } \\
\text { voluntarios, redes de } \\
\text { apoyo gubernamentales } \\
\text { y no gubernamentales } \\
\text { capaces de comprender } \\
\text { la tragedia moral y } \\
\text { espiritual del fenómeno } \\
\text { migratorio. }\end{array}$ \\
\hline $\begin{array}{l}\text { Personal de } \\
\text { la CDMS en } \\
\text { Atención } \\
\text { Jurídica }\end{array}$ & $\begin{array}{l}\text { Visión estructural ligada } \\
\text { al estado de los derechos } \\
\text { humanos, sociales, } \\
\text { económicos y políticos. } \\
\text { El respeto y el avance } \\
\text { progresivo en el derecho } \\
\text { universal a la salud, es el } \\
\text { principio que origina la } \\
\text { posibilidad de salud en } \\
\text { las personas. }\end{array}$ & $\begin{array}{l}\text { Las enfermedades son } \\
\text { consecuencia de factores } \\
\text { estructurales que no han } \\
\text { sido suficientemente } \\
\text { atendidos, ni como } \\
\text { principios normativos } \\
\text { ni como operación } \\
\text { obligatoria en las } \\
\text { instancias públicas. }\end{array}$ & $\begin{array}{l}\text { Lucha por constituir } \\
\text { a la solidaridad como } \\
\text { principio normativo, } \\
\text { como atención } \\
\text { obligatoria del Estado a } \\
\text { los derechos humanos. }\end{array}$ \\
\hline
\end{tabular}

Así, lo que encontramos son definiciones de los conceptos eje de la problemática de riesgos a la salud que los informantes han desarrollado a partir de su experiencia, de sus saberes y de sus objetivos relacionadas con la migración; que han construido en procesos de reflexión individual y conjunta tanto en situaciones emergentes como a través de procesos que han sido guiados por el personal de atención jurídica, médica, humanitaria y psicoeducativa de la CDMS. Los resultados de la investigación permiten destacar entre los contenidos de significados y en el origen de su construcción, dos lecturas diferenciadas - por una parte de las personas migrantes, y por otra, de los líderes, voluntarios y administrativos de la Casa del Migrante- de los riesgos a la salud y de la solidaridad como valor y principio normativo en la experiencia migratoria de los actores.

Por un lado, el significado que a la salud y a la enfermedad le otorgan las personas migrantes se relaciona directamente con su objetivo de traslado, por lo que el cuerpo se convierte en instrumento para alcanzarlo, tanto en su estado físico como anímico. Las causas estructurales relacionadas con la falta de acceso a los servicios de salud o el estrés crónico acumulado desde la infancia no son percibidas por ellos como razón suficiente para dejar su país. Tampoco aparece en su imaginario que los trastornos mentales, tales como la depresión o la ansiedad, sean enfermedades; sino estados pasajeros cuya responsabilidad de recuperación recae exclusivamente en ellos. El Coordinador de Apoyo legal en la CDMS menciona: "Los migrantes no consideran en su salud a la salud mental. Han sido víctimas de violencia en sus países, pero no se dan cuenta del impacto de ello hasta que están fuera de ahí". Por lo tanto, no parecen integrar en su interpretación de salud y enfermedad, que ésta sea resultado de la poca o nula atención a los derechos humanos en sus lugares de origen y en los de su trayecto; como tampoco se perciben como sujetos de derecho que por principio normativo de solidaridad, traducido en justicia internacional (Young, 2006), deben recibir atención institucional de los gobiernos.

Ante esta perspectiva, los informantes migrantes explicaron en los grupos de enfoque que aunque habían tenido prácticas solidarias en sus lugares de origen con sus compatriotas, era a lo largo de su ruta que habían ido haciendo consciente la necesidad de contar con el apoyo del colectivo para su supervivencia; solidaridad que practicaban 
y a la cual recurrían solo en situaciones en que fuera necesario, pues otras estrategias de supervivencia tenían que ver con el autocuidado individual. Identificaban como ejemplos de conducta solidaria las acciones gestionadas por el personal de la CDMS y las realizadas por miembros de la sociedad civil durante su estancia en el albergue. En el sondeo, no obstante, las respuestas en la pregunta " $¿ S e$ considera usted una persona solidaria?” fueron $96 \%$ sí, mientras que el $4 \%$ respondió que no. En la pregunta "¿Considera usted que ha sido más solidario/a en su país de origen que a lo largo de su tránsito hacia su destino final?", las personas migrantes respondieron que sí en un $72 \%$ y que no, en un $28 \%$. Una última pregunta buscaba conocer su percepción sobre la solidaridad como un derecho humano en México, ésta fue "¿Considera que en México son reconocidos los derechos humanos de las personas migrantes?", a lo que un $66 \%$ respondió que sí, y un $34 \%$ que no.

En contraposición, encontramos en los significados atribuidos a la salud y a la enfermedad por parte del personal voluntario y administrativo de la CDMS, que estos son interpretados como el objeto de su trabajo: el estado de salud o enfermedad de las personas migrantes está directamente relacionado con el ejercicio de los derechos humanos universales, de los que es sujeto todo individuo y que son vulnerados en México tanto en el marco legislativo como en la operación política del país por la falta de atención de las instituciones a esta problemática. Por lo tanto, la labor de los voluntarios es concebida por ellos como su ejercicio de prestadores de servicio de un derecho humano; donde la solidaridad aplicada a la situación de vulneración de los migrantes es puesta en práctica a través de acciones de atención sanitaria y de acompañamiento en la enfermedad.

Por su parte, para el personal del área jurídica, salud y enfermedad se relacionan con la defensa de los derechos humanos y sociales, en cuya tarea establecen relaciones de tensión con las entidades públicas, al identificarlas como el origen de los problemas de salud de las personas migrantes así como de la permanencia de la violación a sus derechos humanos. Tres comentarios emitidos durante las entrevistas a los líderes en la CDMS lo evidencian: "No son solidarios [las instituciones públicas de salud] ni me importa que no lo sean, más bien no saben que tienen la obligación de atender a los migrantes. Están rebasados en atención, entonces, menos atienden a los migrantes", declaró el Director de la Casa del Migrante. El Coordinador de Proyectos mencionó:

Los migrantes están expuestos a situaciones de riesgo por violaciones a derechos humanos, realizadas por las mismas autoridades mexicanas: los golpean, los extorsionan, los detienen. Todo esto viene por el Plan Frontera Sur: Ejército; Estación Migratoria; Grupo Beta (Migración); Policía Federal, Marina

y "En el Hospital Universitario y en el Hospital del Magisterio, hemos pagado mucho dinero". Por su parte, el Coordinador de Vinculación y Difusión, hace referencia a las acciones que desde su campo ha sido necesario llevar a cabo:

Hubo varios casos de violaciones a derechos humanos, a través de una rueda de prensa se expuso que las instituciones de salud les negaban el acceso a los migrantes. Lamentablemente las instituciones entienden solamente a base de quejas.

Los anteriores informantes concluyen que hay una ausencia de la persona migrante en la información de salud pública.

Para los integrantes de las áreas de Atención Humanitaria y de Atención Psicoeducativa, la concepción de la enfermedad de las personas migrantes tiene que ver con su estado emocional y espiritual; además del biológico y de su falta de información sobre la violación a sus derechos. De este modo, las acciones de atención se encaminan a la 
construcción de una cultura de paz y solidaridad por medio de actividades recreativas y terapéuticas; y de empoderamiento civil a través de talleres, conferencias y sesiones informativas en los que se discuten temas relacionados con los derechos humanos y el bienestar personal. El director de la CDMS menciona:

"El migrante es una persona dinamitada por lo que vivió antes de venir y por lo que vivió en el camino. La atención en salud mental nos permitiría dejar de estigmatizarlo, porque están en una situación límite".

La solidaridad, considerada por el personal de atención humanitaria y psicoeducativa como valor que fundamenta su práctica, les permite intervenir, desde su punto de vista, el daño estructural causado a los migrantes por la violación a sus derechos humanos a lo largo de su biografía, y empoderarlos ante las injusticias de que son objeto.

\section{Prácticas de resiliencia y autocuidado}

Tobón Correa (2003) define a la resiliencia como la flexibilidad que tenemos las personas de asumir nuestra posición ante situaciones de riesgo y la capacidad de sobreponerse a ellas utilizando todos los recursos internos y externos disponibles. Esta característica de la personalidad, básica para la supervivencia y la realización del autocuidado, no está aislada de otros factores individuales como lo son el autoconcepto o la valoración construidas a partir de las opiniones de los demás; el autocontrol, para tomar decisiones y actuar en consecuencia con ellas; y la autoestima para reconocer en uno mismo cualidades y limitaciones de actuación ante cualquier situación. Además de estos factores, a partir de las experiencias que los migrantes relatan, podríamos agregar que la resiliencia también se construye a partir de factores de influencia externa como la capacidad de empatizar con el otro a partir de su situación de vulnerabilidad, o de solidarizarse en la búsqueda del bienestar común y de llegar al destino.

El asidero más importante para el desarrollo de la resiliencia de los migrantes centroamericanos tiene que ver con la idealización de lograr llegar a Estados Unidos, encontrar allá condiciones de vida más seguras y un ingreso económico suficiente para contribuir con remesas a la economía de los familiares que se quedan en el país de origen. A pesar de que las personas en tránsito relatan la dura situación por la que tienen que pasar en México, sus ilusiones no desaparecen, tal como lo menciona Koselleck (1993):

\section{Así, asumiendo que la experiencia es un pasado presente cuyos acontecimientos han sido incorporados y pueden ser recordados, la expectativa se ve envuelta entonces por sentimientos de esperanza y a la vez temor; deseo y voluntad, inquietud, análisis racionales y curiosidad (citado por Astorga-Morales, 2014:338).}

Para entender mejor el concepto de autocuidado recurrimos a la Organización Mundial de la Salud (1998), la cual lo define como todas aquellas actividades a nivel individual, familiar o comunitario que tienen la finalidad de mantener y restaurar la salud o prevenir y limitar la enfermedad. Como lo menciona Sánchez (2014), hablar de temas sobre autocuidado y promoción de la salud, no es hablar de ellos como elementos aislados, sino como un conjunto de dimensiones entrelazadas que modelan los resultados de salud en las personas. El autocuidado incluye, por lo tanto, una cultura y un estilo de vida que permean en las acciones individuales, el apoyo familiar, la acción comunitaria así como las políticas nacionales e internacionales para mantener y restaurar la salud o prevenir y limitar la enfermedad (OMS, 1986, 1998). El ejercicio del autocuidado puede ser de dos tipos, reactivo y proactivo en la adquisición de habilidades y conocimientos para la vida (Ziguras, 2004). Es un acto de autonomía, pero al mismo tiempo es un acto de reciprocidad grupal que se ofrece a alguien que no está en condiciones de hacerlo por sí mismo. 
El autocuidado pasa por cinco niveles de acción social, inicia con acciones individuales como la alimentación, hidratación, higiene, ejercicio, detección de enfermedades, entre otras, y continúa en planos que involucran a más personas hasta llegar a estructuras sociales más complejas. En el nivel familiar se incluye el apoyo a miembros de la familia que necesitan ayuda para el bienestar; en el nivel comunitario implica la creación y mantenimiento de entornos para promover el bienestar, compartir habilidades, recursos y experiencias; en el nivel político se desarrollan planes, programas y estrategias colectivas y gubernamentales de promoción de la salud; y en el nivel institucional se promueve la cultura de la salud a través de organizaciones de la sociedad civil, las religiones, los medios de comunicación y el sector industrial (Sánchez, 2014).

\section{Prácticas y estrategias para la consolidación de un marco normativo de solidaridad}

Los integrantes de la CDMS, al igual que otras asociaciones civiles en el país, desarrollan acciones de atención a la salud de la población migrante y de defensa de sus derechos humanos ante instituciones públicas. La estrategia a corto y largo plazo, es buscar que las políticas públicas de migración en los tres niveles de gobierno (federal, estatal y municipal), permitan consolidar un estado de solidaridad normativa que pueda dar justa respuesta al fenómeno migratorio en el país. Para el logro de esta meta, se han agrupado en redes de organizaciones que cuentan con el apoyo de organismos internacionales que reconocen a la salud como un derecho humano universal que debe ser garantizado por el Estado a las personas migrantes en tránsito por México. Los resultados de esta investigación arrojan que, para el caso de la CDMS, la alianza con organismos internacionales como el ACNUR, les permite establecer convenios interinstitucionales para la atención a la salud y a los derechos humanos de los migrantes en México, contar con provisión de capital y de recursos de atención para la salud, recibir patrocinios para la ejecución de proyectos en pro de la salud de los migrantes, aportar información para la caracterización de los riesgos de salud física y mental que afectan la condición humana de los migrantes, así como contribuir en la elaboración de informes sobre el estado de los derechos humanos de las personas migrantes en estaciones migratorias y otras entidades públicas con las que se fundamenta la emisión de recomendaciones al Estado para el respeto a los derechos humanos.

Por su parte, ante la falta de atención de instituciones públicas, el personal de la CDMS realiza acompañamiento en la defensa de derechos a la salud pública para personas migrantes; en la tramitación de permisos y solicitudes migratorias (de refugio) ante enfermedades crónicas o accidentes; así como en la búsqueda de otras alternativas de atención como: médicos voluntarios, farmacias de bajo costo, convenios con universidades y asociaciones civiles, búsqueda de patrocinadores de medicinas y recursos para la salud. Estas actividades se realizan junto con la interposición de denuncias por violaciones a los derechos humanos; el seguimiento legal de atención a la salud de los migrantes en centros de salud pública y la realización de convenios con entidades de gobierno para la implantación de campañas de salud en la organización.

$\mathrm{Al}$ interior de la CDMS, los integrantes de sus distintos departamentos actúan de forma colaborativa con la intención de consolidar, a través de estrategias derivadas de su área de intervención, un estado de solidaridad normativa para las personas migrantes en México. Así, los voluntarios realizan actividades de difusión de una cultura de solidaridad, basada en el reconocimiento de los derechos humanos, con respecto al fenómeno migratorio, tanto a nivel nacional como internacional, al participar en proyectos, organismos e iniciativas de sus universidades de origen cuando son estudiantes; y en las asociaciones e instituciones a las que pertenecen, en el caso de los profesionales. El personal de la CDMS en el área de Atención Psicopedagógica y Humanitaria interviene permanentemente en la recuperación y el empoderamiento emocionales de la persona migrante, a través de un servicio caracterizado por la confidencialidad de la 
información, la protección de los derechos y la valoración de la vida humana. Por su parte, los miembros del departamento de Atención Jurídica se encargan de la defensa de los derechos humanos brindando orientación legal a los migrantes albergados en la CDMS para la realización de denuncias de violación a sus derechos humanos y a la salud ante las autoridades en México. Asimismo, su estrategia a corto y mediano plazo es la constante defensa de los derechos humanos como obligación universal que logre el avance progresivo del derecho a la salud para las personas migrantes en la legislación mexicana.

Las personas migrantes albergadas en la asociación realizan, a su vez, prácticas derivadas del significado de solidaridad sanitaria que han construido a partir de su experiencia migratoria. Los hombres, por ejemplo, mencionan que como acción solidaria en el cuidado de la salud, comparten medicamentos, recursos y orientación en situaciones de riesgo con otros migrantes; realizan acompañamiento en enfermedades, situaciones de riesgo o decaimiento físico y anímico, así como orientan a sus compañeros en el trayecto y en la CDMS sobre acciones preventivas y de recuperación de la salud. Las mujeres, por su parte, consideran como acción solidaria su participación en el cuidado de personas migrantes enfermas (sobre todo mujeres y niños), en orientar a otras mujeres sobre la identificación de síntomas de enfermedades y vulneraciones relacionadas con el cuerpo femenino; participar en acciones de salud emocional y de reconocimiento de derechos a través de las actividades promovidas por y en la CDMS, que organizan conjuntamente líderes, administrativos, voluntarios y organismos públicos y privados.

La estrategia global en la CDMS por el reconocimiento jurídico y el avance progresivo de los derechos humanos para la población migrante en México integra, como vemos, actividades que van desde la documentación y denuncia de los casos de sus violaciones, el trabajo participativo y especializado en la recuperación de los traumas físicos y emocionales de las personas migrantes, la construcción de una cultura de solidaridad normativa entre todos los involucrados en la atención a esta población, la difusión y concientización sobre la problemática entre la ciudadanía, hasta el establecimiento de convenios internacionales e institucionales para la formación de redes. Estas actividades, realizadas desde distintos frentes de atención en la CDMS, son representativas de una estrategia compartida por otras asociaciones civiles en el país abocadas a la atención de la población migrante. Su meta final es poder contar con un marco legal que reconozca y garantice el derecho a la salud, entre otros derechos humanos, como cristalización de una solidaridad normativa que resulta imprescindible establecer ante la deuda histórica de desigualdad que se presenta hacia la población migrante así como ante el vacío de una justa política de movilización humana en un mundo de globalización neoliberal a toda marcha:

(...) En medio de la complejidad que ha adquirido la sociedad en un mundo de globalización, donde no existe árbitro, el único actor que decide el destino de los seres humanos es el mercado. Desde que emprenden el viaje, los migrantes entran en un proceso contradictorio que se caracteriza, por una parte, por la desvalorización de su condición humana, moral y física; sin embargo, por otra parte, van generando una cadena de valor al entrar en contacto con los actores que integran la llamada industria de la migración, incluyendo a los secuestradores y los extorsionadores. Los que logran pasar la frontera y conseguir un empleo, de lo que sea, comienzan una nueva etapa para reponer lo que les han quitado; tendrán que pasar hambre, vivir hacinados y dormir mal para poder reunir dinero y pagar sus deudas. La lógica de la supervivencia en donde impera la exclusión impone altísimos sacrificios para los migrantes que están dispuestos a morir en el intento de cruzar la frontera con Estados Unidos (García y Villafuerte, 2014). 


\section{Conclusiones}

En este trabajo hemos dado cuenta de cómo se construyen, cuáles son los contenidos, qué experiencias determinan y a qué acciones conducen los significados que a los términos salud, enfermedad y solidaridad le dan los diversos actores involucrados en la atención a las personas migrantes centroamericanas en su paso por México, a través del análisis de esta dinámica en la Casa del Migrante de Saltillo (CDMS).

Las prácticas de cuidado de la salud por parte de personas migrantes así como de los miembros voluntarios y administrativos de la CDMS descritas en apartados anteriores, dan cuenta de la respuesta: ante el aumento de riesgos a la salud y a la integridad física de las personas migrantes en territorio mexicano, el desarrollo de su resiliencia y de habilidades para el autocuidado aparece como área primordial a intervenir por parte de los organismos de la sociedad civil, con una concepción de solidaridad normativa (ejercicio de justicia social frente al reconocimiento de las condiciones estructurales de desequilibrio global) que estos promueven a través de la defensa de los derechos humanos y de la divulgación de información para la comprensión pública del problema.

Por su parte, a partir de los testimonios y experiencias recabadas con las personas en la Casa del Migrante de Saltillo, coincidimos con otros investigadores (Botero y Gordon, 2013; López, 2013; Barja Coria, 2015; Leyva, et al, 2015) en que los migrantes presentan daños en su salud física y mental debido a las condiciones y traumas que enfrentan durante su viaje para cruzar hacia Estados Unidos, y que estos riesgos se agravan cuando la persona migrante normaliza las situaciones de vulnerabilidad a las que se expone y acepta la violencia y la indisponibilidad de los servicios de salud institucionalizados por miedo a las autoridades y por el desconocimiento de sus derechos para atenderse en caso de necesitarlo.

Ante esta situación, mientras los miembros y voluntarios de la CDMS trabajan sistemática y cotidianamente en la construcción de una cultura de defensa de los derechos humanos, autocuidado y resiliencia, son los mismos migrantes quienes reportan que a raíz de los riesgos físicos y emocionales que enfrentan en su trayecto así como de las actividades en las que participan para su recuperación individual y colectiva durante su estancia en el albergue, resignifican los significados que le otorgan a los conceptos que tenían antes de iniciar su ruta migratoria sobre salud, enfermedad y solidaridad: si bien conciben a la salud y a la enfermedad como aquello que les permite o les impide lograr su meta (llegar a los Estados Unidos), van integrando en su concepción una clasificación de qué peligros o condiciones pueden y deben ser atendidos de forma colectiva, apelando a una solidaridad práctica y normativa.

Por otra parte, los migrantes perciben a las enfermedades físicas y mentales como situaciones distantes y tienen la idea de que a ellos no les suceden, posiblemente como resultado de la estigmatización social que existe tanto de la condición migrante como de las enfermedades que pueden generarse en el proceso migratorio. Los significados individuales y compartidos de salud y enfermedad de los migrantes tienen un impacto negativo en la percepción de que son sujetos de derecho a la atención en salud y a la generación de estrategias de resiliencia, pues como señalan Temores-Alcantar et al. "a pesar de requerir algún tipo de atención en salud, son los factores socioculturales e institucionales los que generan que los migrantes se autoexcluyan del beneficio de este tipo de servicios" (2015:231).

De modo tal que si bien la ruta migratoria presenta enormes y nuevos riesgos a la salud de las personas migrantes, también se evidencia con los resultados de este trabajo que, en mayor o menor medida, la comunidad construida en torno a la atención de este problema (migrantes; voluntarios, administrativos y miembros de la CDMS) genera 
nuevas concepciones y prácticas colectivas para la consolidación de una cultura de solidaridad normativa que pueda paliar y prevenir las condiciones de inseguridad y deshumanización del fenómeno migratorio en México.

Finalmente, consideramos que no es posible comprender el desarrollo de significados y prácticas de salud, autocuidado, resiliencia y solidaridad por parte de los actores que experimentan y atienden esta problemática migratoria particular, sin atender a la condición de violencia estructural de la que estas vulneraciones son resultado, tal como lo expresan García y Villafuerte (2014) al analizar las posturas y actuaciones de los gobiernos que en norte y sur, contradictoriamente, impulsan y rechazan a conveniencia neoliberal, los flujos migratorios a nivel mundial: "la migración no puede ser contenida sin cambiar las condiciones que la hacen posible: pobreza, exclusión social, desempleo, violencia, cambio climático, las asimetrías entre regiones y países; etc." (124).

Aclaración. Los autores agradecemos a Gibrán Alejandro Valdez Flores, Sergio Antonio García Ríos, Adriana América Miranda Camacho, Alejandra Rodríguez Zamarripa, Aída Graciela Hernández Chávez y Brenda Azucena Muñoz Yáñez el apoyo prestado en la recolección de información en la CDMS para la realización de esta investigación. 


\section{Q Bibliografía}

"Alto Comisionado de las Naciones Unidas para los Refugiados (ACNUR). (2019). Datos básicos: anuarios estadísticos. Recuperado de: https://www.acnur.org/ es-mx/datos-basicos.html (15/06/2019).

» Arango, A. (2013). Solidaridad en la historia de Occidente. Revista de Estudios Sociales, (46), 185-188.

»Arquitectos con la gente. (2016). Mapeo Ruta Migrante. Recuperado de: http:// arquitectosconlagente.com/ruta-migrante-mapeo/ (25/06/2019)

"Agence France-Presse (2019). 15 mil elementos de la Guardia Nacional impedirán el cruce de migrantes hacia Estados Unidos. Recuperado de https:// www.animalpolitico.com/2019/o6/guardia-nacional-migrantes-frontera-eu/ (1/07/2019).

» Astorga-Morales, A. (2014). Del sueño americano al desencanto mexicano. Experiencia y expectativa en la experiencia de migrantes centroamericanos a su paso por México. Temas de Nuestra América. Revista de Estudios Latinoamericanos, 30(56), 15-30.

" Barja Coria, J. (2015). Derechos cautivos. La situación de las personas migrantes y sujetas a protección internacional en los centros de detención migratoria: siete experiencias de monitoreo desde la sociedad civil. Ciudad de México. México: Sin Fronteras IAP.

»Berger, P. L. y Luckmann, T. (2003). La construcción social de la realidad. Buenos Aires: Amorrortu.

"Botero, A. y Gordon, G. (2013). Derechos humanos de los migrantes y otras personas en el contexto de la movilidad humana en México. Ciudad de México, México: Comisión Interamericana de Derechos Humanos.

»Cabrera García, A.C., González Pérez, B. y Paz Jiménez, J.M. (2017). La 'escasa' distancia entre las fronteras norte y sur de México como expresión del régimen de deportación global. Tla-Melaua, 11(43), 200-220.

" Canales Cerón, A.I. y Rojas Wiesner, M.L. (2018). Panorama de la migración internacional en México y Centroamérica. Serie Población y Desarrollo № 124. Santiago: Naciones Unidas - Cepal

"Casa del Migrante de Saltillo. (2019). Recuperado de https://cdmsaltillo.wixsite. com/cdmsaltillo (25/06/2019).

"Colegio de la Frontera Norte (2019). La caravana de migrantes centroamericanos en Tijuana 2018-2019. Recuperado de https://observatoriocolef.org/wpcontent/uploads/2019/03/20.-Reporte-Caravana-Tijuana.250319_compressed1. $\operatorname{pdf}(1 / 07 / 2019)$

"Conferencia del Episcopado Mexicano. (2019). Estudio sobre las casas de migrantes católicas. Recuperado de http://www.cem.org.mx/Slider/58-ESTUDIOSOBRE-LAS-CASAS-DE-MIGRANTES-CAT\%C3\%93LICAS.html. (25/06/2019).

»Consejo Nacional de Población CONAPO. (2016). Índice de marginación por entidad federativa y municipio 2015. Ciudad de México: CONAPO. Recuperado de: https://www.gob.mx/conapo/documentos/indice-de-marginacion-porentidad-federativa-y-municipio-2015 
"Durkheim, E. (1928). La división del trabajo social. Madrid: Daniel Jorro Editor.

"Fundación para la justicia. (2013). Albergues y Casas del migrante en México y Guatemala. Recuperado de: http://fundacionjusticia.org/albergues-y-casasdel-migrante-en-mexico-y-centroamerica/ (20/06/2019)

»García, M.C. y Villafuerte, D. (2014). Migración, derechos humanos y desarrollo. Aproximaciones desde el sur de México y Centroamérica. Chiapas: Universidad de Ciencias y Artes de Chiapas y Juan Pablos Editor.

»Institute for Economics and Peace IEP. (2019). Índice de Paz México 2019. Sidney: IEP. Recuperado de: http://visionofhumanity.org/app/uploads/2019/o4/MPI2019-ESP-Report-web.pdf

" Instituto Nacional de Estadística, Geografía e Informática (2019). Territorio de México. Disponible en: http://cuentame.inegi.org.mx

»Instituto Nacional de Migración. (2019). Estadística reciente de personas presentadas ante la autoridad migratoria. Recuperado de: https://www.gob. $\mathrm{mx} / \mathrm{cms} /$ uploads/attachment/file/460751/ESTADISTICAS.pdf (25/06/2019).

» Human Rights Watch (2019). México desplegará a su Guardia Nacional para enfrentar a familias migrantes. Recuperado de https://www.hrw.org/es/ news/2019/06/12/mexico-desplegara-su-guardia-nacional-para-enfrentarfamilias-migrantes (1/07/2019).

»Leyva Flores, R. Infante, C. Serván Mori, E. Quintino, F. y Silverman-Retana, O. (2015). Acceso a servicios de salud para los migrantes centroamericanos en tránsito por México. CANAMID Policy Brief Series, PBo5. Guadalajara, México: CIESAS.

» Mora Mendoza, B. (2011). Solidaridad familiar y resiliencia. Documentos de Trabajo Social, 51, 99-120.

» Organización Internacional para las Migraciones (OIM). (2012). Migración Saludable en América Central. San José, Costa Rica: OIM.

» Organización Internacional para las Migraciones (OIM). (2016). Estrategia Regional de la OIM para Centroamérica, Norteamérica y el Caribe. San José, Costa Rica: OIM.

»Organización Internacional para las Migraciones (OIM). (S/F). Migrantes saludables en comunidades saludables. Recuperado de: https://www.iom.int/es/ migracion-y-salud (20/06/2019).

»Organización Internacional para las Migraciones (2018). Informe sobre las Migraciones en el Mundo 2018. Ginebra: OIM.

» Organización Internacional para las Migraciones (2018). OIM. (2018). Migration Health Annual Report 2017. Geneva: IOM

» Organización Mundial de la Salud (OMS) (2016). Preguntas frecuentes sobre salud y migración. OMS Recuperado de http://www.who.int/features/qa/88/es/ (18/06/2019).

» Organización Mundial de la Salud (OMS) (1998). Promoción de la salud. Glosario. Ginebra: WHO.

» Organización Mundial de la Salud (OMS) (1986). Ottawa Charter for Health Promotion.Ottawa: WHO.

"Plan de Acción Brasil (2018). Evaluación elaborada por el Grupo Articulador de México. Recuperado de: http://asylumaccess.org/wp-content/uploads/2018/o2/ 
mexico-con-portada-en-paginas.pdf (24/06/2019).

»Red de Documentación de las Organizaciones Defensoras de Migrantes (REDODEM). (2017). El Estado indolente: recuento de la violencia en la ruta migratoria y perfiles de movilidad en México. Informe 2017. Recuperado de: https://fm4pasolibre.org/wp-content/uploads/2018/10/Informe_REDODEMilovepdf-compressed.pdf. (20/06/2019).

"Red de Documentación de las Organizaciones Defensoras de Migrantes (REDODEM). (2015). Migración en tránsito por México: rostro de una crisis humanitaria internacional. Informe 2015. Recuperado de: https://www. entreculturas.org/sites/default/files/informe_redodem.pdf. (20/06/2019).

"Red de Documentación de las Organizaciones Defensoras de Migrantes (REDODEM). (2014). Migrantes invisibles, violencia intangible. Informe 2014. Recuperado de: https://fm4pasolibre.org/wp-content/uploads/2018/o7/ informe_migrantes-invisibles_redodem2014.pdf. (20/06/2019).

"Red de Documentación de las Organizaciones Defensoras de Migrantes (REDODEM). (2017) El estado indolente: recuento de la violencia en la ruta migratoria y perfiles de movilidad en México. Informe 2017. Recuperado de: https://fm4pasolibre.org/wp-content/uploads/2018/10/Informe_REDODEMilovepdf-compressed.pdf (29/06/2019)

»Rodríguez García, A. (2011, octubre 11). Premian a Casa del Migrante de Saltillo. Proceso.com.mx. Recuperado de https://www.proceso.com.mx/283840/ premian-a-casa-del-migrante-de-saltillo (27/06/2019).

» Roth, K. (2019). Los autócratas del mundo se enfrentan a una creciente resistencia. Informe anual 2019 de Human Rights Watch. Recuperado de https://www.hrw.org/es/world-report/2019/country-chapters/325815\#914843 (1/07/2019).

»Sánchez Maldonado, M. (2014). El autocuidado de los hombres. Prácticas y significados del autocuidado de los hombres de clase trabajadora de Saltillo, Coahuila desde la comunicación para la salud. Tesis de doctorado. Monterrey: Tecnológico de Monterrey.

» Schutz, A. (1993). La construcción significativa del mundo social. Introducción a la fenomenología comprensiva. Barcelona: Paidós.

"Secretaría de Salud, Gobierno de México (2019). Seguro Popular. Recuperado de: https://www.gob.mx/salud/seguropopular/es/\#6157 (30/10/2019)

»Strauss, A. y Corbin, J. (2002). Bases de la investigación cualitativa. Técnicas y procedimientos para desarrollar la teoría fundamentada. Antioquia: Universidad de Antioquia.

»Suárez, X., Díaz, A., Knippen, J. y Meyer, M. (2017). El acceso a la justicia para las personas migrantes en México. Un derecho que existe solo en el papel. Cd. De México: Red Migrante Sonora, Hermanos en el Camino, Hogar Refugio para Migrantes Tenozique Tabasco, Casa del Migrante de Saltillo, Fundación para la Justicia y el Estado de Democracia en México, FUNDAR Centro de Análisis e Investigación, WOLA. Recuperado de https://www.wola.org/wp-content/ uploads/2017/o7/Accesoalajusticia_Versionweb_Julio20172.pdf

» Temores-Alcántara, G., Infante, C., Caballero, M., Flores-Palacios, F., y Santillanes-Allande, N. (2015). Salud mental de migrantes centroamericanos indocumentados en tránsito por la frontera sur de México. Salud Pública de México, 57(3), 227-233. 
» Tobón Correa, O. (2003). El autocuidado. Una habilidad para vivir. Hacia la promoción de la salud, 8, 41-45.

» Young, I. M. (2011). Responsability for Justice. Nueva York: Oxford University Press.

»Zamudio. A. Caudillo. C. (2015). La movilidad laboral guatemalteca en México (2010-2012). Un estudio con enfoque espacial. Espacialidades, 5(2), 177-206.

"Ziguras, C. (2004). Self-Care. Embodiment, personal autonomy and the shaping of health consciousness. Londres: Routledge.

\section{Gabriela de la Peña Astorga / gabriela.pena@uadec.edu.mx}

Licenciada y Maestra en Ciencias en Comunicación por el Tecnológico de Monterrey, Campus Monterrey. Doctora en Antropología del Espacio y el Territorio por la Universidad de Barcelona. Profesora investigadora de tiempo completo en la Universidad Autónoma de Coahuila. Miembro del Sistema Nacional de Investigadores (Nivel 1) del CONACYT. Cultiva las líneas de investigación en comunicación de la diversidad para el desarrollo social, espacios públicos urbanos y educomunicación.

\section{Miguel Sánchez Maldonado / miguelsanchez@uadec.edu.mx}

Licenciado y Maestro en Comunicación por la Universidad Autónoma de Coahuila y Doctor en Estudios Humanísticos por el Tecnológico de Monterrey. Profesor investigador de tiempo completo en la Universidad Autónoma de Coahuila. Miembro del Sistema Nacional de Investigadores (Nivel 1) del CONACYT. Cultiva las líneas de investigación en comunicación para la salud, estudio de masculinidades y comunicación de la diversidad para el desarrollo social.

\section{Sergio de Jesús Colunga Corpus / s.colunga@uadec.edu.mx}

Estudiante de la licenciatura en Comunicación Organizacional y Relaciones Públicas en la Universidad Autónoma de Coahuila. Voluntario y Pasante en el área de Vinculación e Incidencia en la Casa del Migrante de Saltillo. Voluntario en la asociación FM4 Paso Libre en Guadalajara, México. 